\title{
ANALISIS PERUBAHAN SIFAT PELUMAS TERHADAP KEAUSAN DAN PERFORMA MESIN SAA12V140E-3 KOMATSU HD785-7
}

\author{
Novendra David Rizaldy \\ Departemen Teknik Mesin, Sekolah Vokasi, \\ Universitas Gadjah Mada \\ JIn. Yacaranda, Sekip Unit VI, Catur Tunggal, \\ Yogyakarta 55281, Indonesia \\ novendra.david.rizaldy@mail.ugm.ac.id
}

\author{
Susanto Johanes* \\ Departemen Teknik Mesin, Sekolah Vokasi, \\ Universitas Gadjah Mada \\ JIn. Yacaranda, Sekip Unit VI, Catur Tunggal, \\ Yogyakarta 55281, Indonesia \\ s.johanes@ugm.ac.id \\ *corresponding author
}

\section{ABSTRAK}

Penurunan viskositas pada pelumas engine berpengaruh terhadap sifat pelumas sehingga bisa menyebabkan kerugian gesek dan peningkatan konsumsi bahan bakar. Selain itu, pelumas dengan viskositas rendah akan menyebabkan tingkat keausan yang lebih tinggi dan kurangnya performa engine.

Penelitian ini menguji pelumas mesin SAA12V140E-3 dari Komatsu HD785-7 dengan program pemeriksaan mesin (PPM), overhaul engine, pengukuran inner part dan dyno test. Setelah engine selesai overhaul, selanjutnya melakukan inspeksi pada inner part untuk mengetahui apakah komponen dapat digunakan lagi, harus diganti atau diperbaiki.

Hasil pengujian dan pengukuran menunjukkan bahwa tingkat keausan inner part pada mesin SAA12V140E-3 masih normal. Performa mesin sesudah overhaul mengalami peningkatan mencapai $94 \%$ atau hampir mendekati performa mesin baru.

Kata kunci: Pelumas, engine overhaul, sifat pelumas.

\section{PENDAHULUAN}

Keausan terjadi apabila dua buah benda yang saling menekan dan bergesekan. Keausan lebih besar terjadi pada bahan yang lunak. Faktor-faktor yang mempengaruhi keausan adalah kecepatan, tekanan, kekasaran permukaan dan kekerasan bahan. Semakin besar kecepatan relatif benda yang bergesekan, maka material semakin aus [1] [2]. Demikian pula semakin besar tekanan pada permukaan benda yang kontak, maka material akan cepat aus. Keausan mengakibatkan terkelupasnya material pada permukaan benda hingga menyebabkan kerusakan benda tersebut. Untuk mengatasi keausan biasanya diberikan pelumas [3] [4].

Pelumasan komponen engine berdasarkan pada kecepatan, tekanan, dan temperatur. Penurunan viskositas pelumas engine harus diperhatikan karena akan berpengaruh terhadap sifat pelumas. Proses pelumasan mengalami peningkatan kerugian gesek dan konsumsi bahan bakar. Selain itu, pelumas dengan viskositas rendah menyebabkan tingkat keausan yang lebih tinggi. Hal ini jika tidak segera diselesaikan akan menambah biaya perawatan dan mengurangi umur engine serta berakibat pada meningkatnya biaya operasi secara keseluruhan. Pelumas dengan viskositas rendah dapat mengurangi gesekan hidrodinamik [3].

Rumusan dari penelitian ini adalah menganalisis pengaruh perubahan sifat pelumas terhadap keausan inner parts pada engine diesel dump truck Komatsu HD785-7. Analisis ini memeriksa kandungan pelumas dan melakukan pengukuran inner parts. Beberapa hasil program analisis pelumas menemukan kandungan material yang berbeda-beda yang dapat digunakan untuk mengetahui tingkat keausan pada inner parts. Berdasarkan permasalahan di atas, maka tujuan penelitian ini adalah untuk mengetahui:

1. tingkat keausan inner part berdasarkan data program analisis pelumas.

2. performa engine selama pengoperasian berdasarkan data Vehicle Health Monitoring System (VHMS).

3. performa engine sebelum proses overhaul berdasarkan data program pemeriksaan mesin (PPM).

4. keausan inner part setelah engine overhaul.

5. performa engine setelah proses overhaul berdasarkan data dyno test.

Batasan dalam penelitian ini adalah:

1. analisis keausan pada inner part hanya pada bagian bearing.

2. Data diambil dari tujuh sampel program analisis pelumas terakhir

3. menggunakan data PPM terakhir dan VHMS.

4. analisis dyno test setelah proses overhaul.

\section{TINJAUAN PUSTAKA}

Dump truck Komatsu HD785-7 menggunakan engine tipe SAA12V140E-3. Engine ini memiliki akselerasi, kecepatan dan daya tiap tonn yang tinggi. Sistem injeksi High Pressure Common Rail (HPCR), air to air aftercooler dan turbocharger memungkinkan engine menjadi emisi EPA tier 2 yang memberikan daya output bersih maksimum 1200 HP. Torsi yang tinggi pada kecepatan rendah, akselerasi tingi dan konsumsi bahan bakar yang rendah memastikan produktivitas tinggi. Teknologi HD785-7 memiliki konsumsi bahan bakar yang rendah, keamanan dan kenyamanan untuk operator, serta peningkatan daya tahan dan kehandalan tinggi.

Dalam mesin terdapat kontak mekanik antara elemen mesin satu dengan yang lainnya. Kontak mekanik ini merupakan salah satu penyebab terjadinya keausan (wear). Keausan ini harus dihindari untuk 
elemen mesin yang mentransmisikan daya.

Abrasive wear adalah jenis keausan yang terjadi apabila permukaan yang lebih unak, mengalami goresan (Gambar 1). Abrasi juga bisa disebabkan oleh partikel keras diantara permukaan yang saling kontak. Fragment abrasive dalam fluida yang mengalir cepat juga dapat menyebabkan abrasi permukaan. Jika partikel keras tersebut masuk ke dalam sistem pelumasan maka pencegahannya adalah mengeliminasi kontaminan keras tersebut.

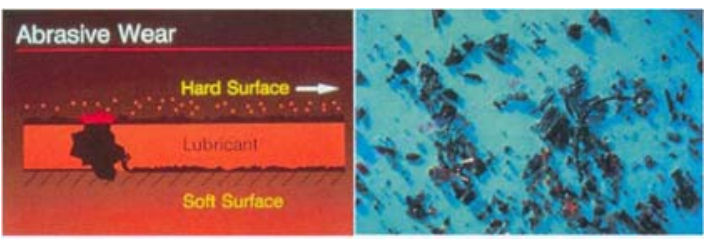

Gambar 1. Abrasive wear (PT Trakindo).

Faktor yang terkait dengan ketahanan material terhadap abrasive wear antara lain:

1. kekerasan dan struktur mikro material.

2. ukuran partikel abrasive.

3. geometri.

Bentuk kerusakan permukaan akibat keausan abrasive, antara lain:

1. scratching.

2. scoring.

3. gouging.

Program Pemeriksaan Mesin adalah program pemeliharaan berupa inspeksi rutin pada peralatan alat berat. PPM meliputi pemeriksaan sistem hidrolik mesin, chassis dan perlengkapan operasi lainnya. Program ini nantinya dapat meningkatkan performa mesin, penyesuaian dan analisis saat inspeksi mesin. Hasil inspeksi berupa rekomendasi perbaikan yang dibutuhkan agar peralatan tetap berada pada kondisi prima.

\section{METODE PENELITIAN}

\section{Lokasi dan Waktu Penelitian}

Penelitian dilaksanakan di Workshop PT Saptaindra Sejati, Jalan Raya Narogong Km. 14, Pangkalan V, Bantargebang, Bekasi, antara bulan Januari hingga April 2019.

\section{Alat Penelitian}

Pengambilan data sebagai bahan analisis pada penelitian ini membutuhkan beberapa peralatan. Alatalat yang digunakan terdiri dari alat utama dan pendukung sebagai berikut:

1. Alat utama

Engine diesel SAA12V140E-3 unit dump truck Komatsu HD785-7 dengan spesifikasi pada Tabel 1.

\section{Alat pendukung}

Vernier calliper, micrometer, cylinder bore gauge dan dyno test

Jurnal Material Teknologi Proses (ISSN: 2477 - 2135), Volume 2, Nomor 1, Tahun 2021

DOI: $10.22146 /$ jmtp.66065
Tabel 1 Spesifikasi Engine

\begin{tabular}{cc}
\hline Engine Type & Common Rail Injection \\
\hline Engine Serial Number & 503073 \\
Engine Model & SAA12V140E-3 \\
Number of Cylinder & 12 Cylinder \\
Number of Valve & Valve \\
Fuel Type & Diesel \\
Cylinder Bore & $140 \mathrm{~mm}$ \\
Piston Stroke & Square Stroke \\
Rated Power & $1160-1240 / 1900+-50$ \\
Firing Order & $1-5-3-6-2-4$ \\
\hline
\end{tabular}

\section{Tahap Pengambilan Data}

Proses pengambilan data adalah sebagai berikut:

1. Pengambilan sampel analisis pelumas.

2. Pengambilan data VHMS.

3. Proses PPM.

4. Pengukuran keausan inner part setelah engine overhaul

5. Tes performa engine setelah overhaul (dyno test)

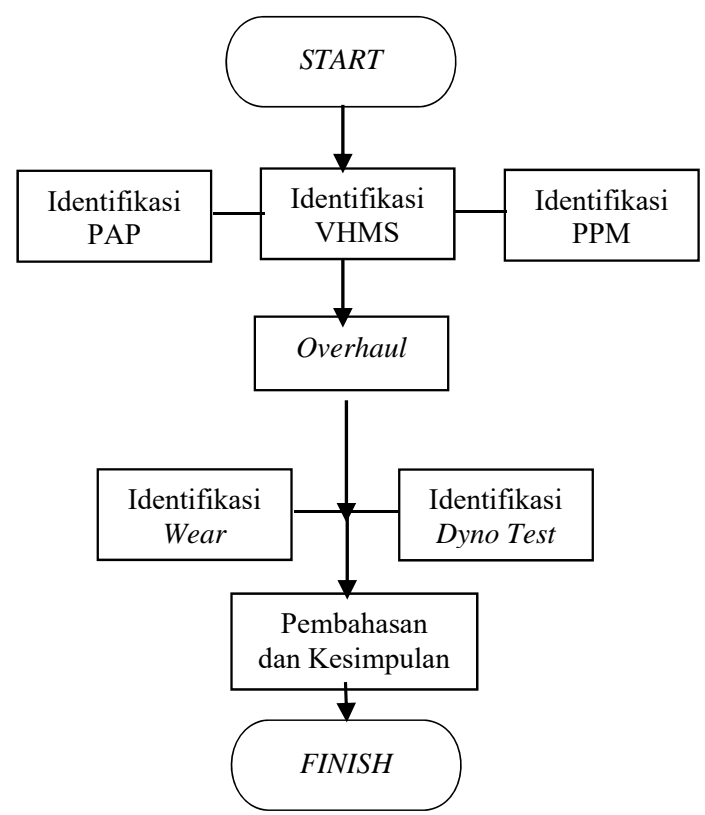

Gambar 2. Proses penelitian.

\section{Tahap Pengelompokan Data}

Data dalam penelitian ini diperoleh dari:

\section{Data Primer}

Data primer yaitu data yang diperoleh secara langsung melalui pengukuran dan pembacaan pada alat dan dari bacaan alat ukur pada masing-masing pengujian.

a. Data program Analisis pelumas

Program Analisis Pelumas atau PAP adalah hasil analisis pelumas yang diserahkan kepada Oil Sampling Analysis (OSA) untuk dilakukan uji sampling pelumas. Data ini berfungsi sebagai bukti kondisi pelumas engine di dalam engine system.

b. Data VHMS

VHMS adalah hasil pemeriksaan sistem engine yang diunduh dengan personal computer (PC). 
Tujuannya adalah untuk mengetahui kondisi engine pada masing-masing sistem.

\section{c. Data PPM}

PPM adalah hasil pemeriksaan yang dilakukan oleh mekanik untuk mengetahui kondisi engine setelah beroperasi.

d. Data pengukuran inner part

Pengukuran inner part dilakukan untuk mengetahui tingkat keausan komponen tersebut.

e. Data Dyno Test

Dyno test merupakan data hasil pemeriksaan performa engine setelah dilakukan overhaul.

\section{Data Sekunder}

Data sekunder adalah data yang diperoleh dari hasil pengujian pelumas pada diesel engine yaitu kandungan pelumas, tingkat keausan pada inner parts, serta hasil dari PPM dan VHMS.

\section{Tahap Analisis Hasil}

1. Pengelola Data

Data-data PAP, PPM, VHMS, pengukuran keausan inner part, dan dyno test, kemudian diolah untuk menentukan langkah awal menganalisis laju keausan inner part dan perbandingan performa mesin saat inner part aus dan saat tidak aus.

2. Analisis Data

Setelah semua data diolah, analisis dilakukan untuk menemukan komponen yang mengalami keausan sehingga unit mengalami penurunan performa.

3. Kesimpulan

Hasil olah data dan analisis akan menghasilkan kesimpulan tentang laju keausan inner part dan performa mesin.

\section{HASIL DAN PEMBAHASAN}

Penelitian untuk mengetahui pengaruh perubahan pelumas terhadap keausan inner part dilakukan dengan mengukur tingkat keausan komponen tersebut. Data hasil pengukuran dipadukan dengan data PAP untuk mengetahui laju keausan setiap komponen inner part. Data PPM dan engine dyno test digunakan untuk membandingkan daya dan torsi engine antara kondisi komponen aus dengan kondisi komponen baru (belum aus). Pengukuran inner part dilakukan di beberapa titik.

\section{Program Analisis Pelumas}

Pengujian sampel pelumas engine

SAA12V140E3 dilakukan menggunakan alat On Site Analyzer atau OSA. Dalam analisis pelumas terdapat contamination control, yaitu sebuah upaya untuk mengontrol tingkat kontaminasi sekecil mungkin. Tujuannya menghindari kontaminasi yang dapat merusak komponen-komponen atau menggangu proses kerja. Berikut ini adalah data hasil pengujian:

\section{Analisis Kandungan Wear Metal}

Gambar 3 memperlihatkan nilai kandungan $\mathrm{Pb}$ yang mengalami penurunan pada operasi tiga bulan terakhir. Kandungan $\mathrm{Pb}$ pada engine terdapat pada lapisan metal bearing. Saat awal engine beroperasi, kandungan $\mathrm{Pb}$ cukup tinggi untuk membantu mengatasi gesekan crankshaft dan connecting rod yang dapat menyebabkan bearing menjadi aus. Lapisan kedua pada bearing setelah $\mathrm{Pb}$ adalah $\mathrm{Cu}$.

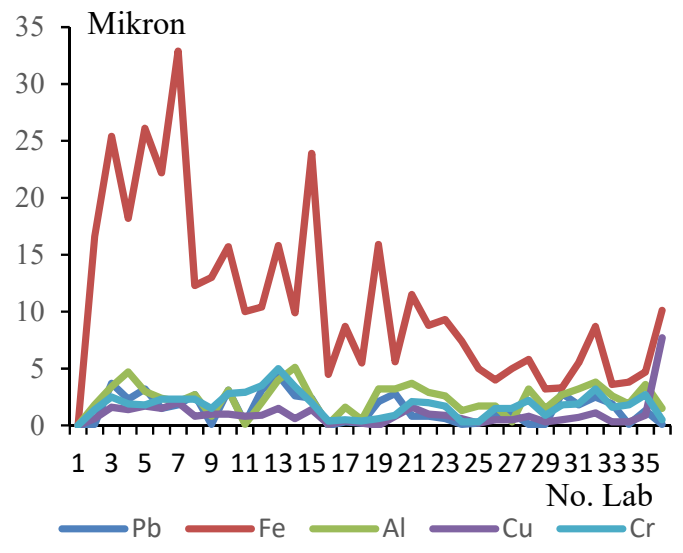

Gambar 3. Grafik wear metal.

Nilai contaminant $\mathrm{Cu}$ pada dua bulan terakhir mengalami kenaikan rastis. Komponen yang mengandung $\mathrm{Cu}$ dari lapisan kedua bearing (near failure) adalah wrist pin bushing, cam bushing, oil cooler, valve tran bushing, governor, dan oil pump. Jika lapisan $\mathrm{Pb}$ dalam bearing sudah tidak ada, maka keausan akan terjadi pada lapisan kedua. Saat kandungan $\mathrm{Pb}$ sudah turun, maka kandungan $\mathrm{Cu}$ menjadi lebih tinggi.

Unsur selanjutnya adalah $\mathrm{Fe}$. Nilai $\mathrm{Fe}$ pada operasi tiga tahun merupakan contaminant tertinggi dibanding contaminant yang lain. Keausan komponen yang dengan unsur Fe adalah cylinder liner, gear, ring piston, lapisan ketiga bearing, crankshaft, wrist, pin, camshaft, valve train, dan oil pump. Pada sampel awal, kandungan contaminant Fe sangat tinggi. Hasil uji ke 20 hingga uji ke 34 menunjukkan penurunan trend kandungan Fe. Hal ini terjadi karena gesekan pada komponen yang mengandung Fe semakin berkurang.

Kandungan Al pada Gambar 3 relatif normal dan tidak ada kenaikan yang siginifikan. Komponen di dalam engine yang mengandung $\mathrm{Al}$ adalah piston, bearing, bushing, block, houshing, oil pump bushing, blower, thrust bearing, dan cam bearing. Gesekan terjadi antara piston (banyak mengandung $\mathrm{Al}$ ) dengan cylinder liner (dominan mengandung Fe). Tingginya unsur $\mathrm{Fe}$ dan stabilnya kadar $\mathrm{Al}$ dalam pelumas menunjukkan bahwa tingkat keausan cylinder liner lebih tinggi dibandingkan dengan piston.

Sama dengan kandungan $\mathrm{Al}$, kandungan $\mathrm{Cr}$ juga relatif normal dan rendah. Komponen di dalam engine yang mengandung $\mathrm{Cr}$ adalah ring, roller, taper bearing, exhaust valve, dan water treatment.

\section{Analisis Contaminants}

Gambar 4 menunjukkan data program analisis pelumas. Bahan pelumas ternyata mengandung silikon 
dan sodium. Silikon dapat meyebabkan timbulnya gumpalan yang mengikis permukaan logam selama engine beroperasi. Keberadaan kandungan silikon, Fe, dan $\mathrm{Al}$, menunjukkan adanya kotoran dalam porsi rendah pada engine. Hal ini dapat dipakai sebagai petunjuk tentang terjadinya keausan pada crankshaft dan bearing.

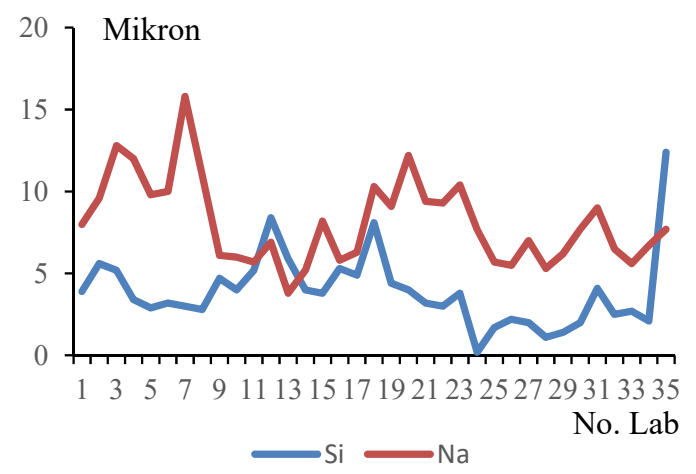

Gambar 4. Grafik contaminants.

Kandungan sodium yang paling besar terdapat di dalam coolant. Keberadan unsur tersebut mengindikasikan adanya kebocoran coolant yang masuk ke dalam sistem pelumasan. Selanjutnya terdapat kandungan air di dalam engine yang menjadi mengindikasi terjadinya kontaminasi dari luar, baik karena embun atau kebocoran air pendingin. Kontaminasi coolant atau air dalam pelumas dapat mempercepat terjadinya oksidasi (karat) pada komponen mesin.

\section{Analisis Infrared}

Gambar 5 menunjukkan kandungan jelaga pada pada pelumas dengan kenaikan dan penurunan yang siginifikan. Kenaikan kadar jelaga dalam pelumas disebabkan oleh air intake yang tersumbat, kekurangan dalam sistem bahan bakar atau oleh terjadinya perubahan cara operasi mesin. Kandungan jelaga yang tinggi tidak langsung menyebabkan kerusakan mesin, tetapi partikel ini mudah terurai dan menyumbat oil filter serta menyusutkan bahan aditif dispersant.

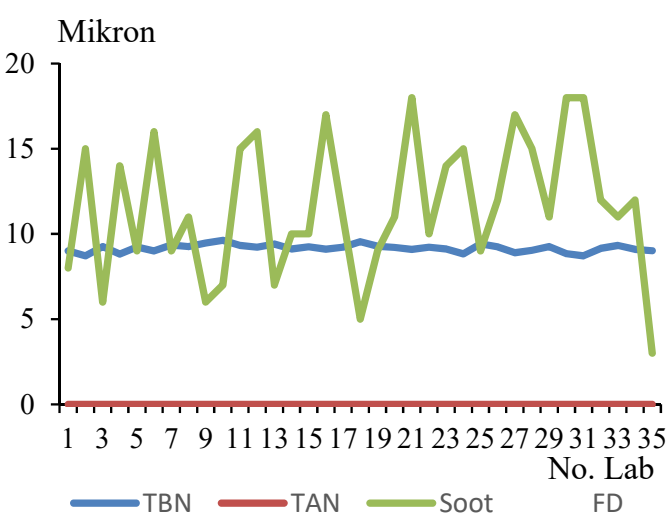

Gambar 5. Grafik Infra-red.
Total Base Number (TBN) relatif normal dan stabil. Angka TBN ini menunjukkan kemampuan pelumas untuk menyerap asam korosif seperti asam mineral yang terbentuk dari sulfur, chlorine, dan bromine.

\section{Analisis Physical Test}

Gambar 6 menunjukkan kandungan air dalam pelumas adalah nihil, sedangkan kandungan fuel dalam pelumas mengalami kenaikan signifikan.

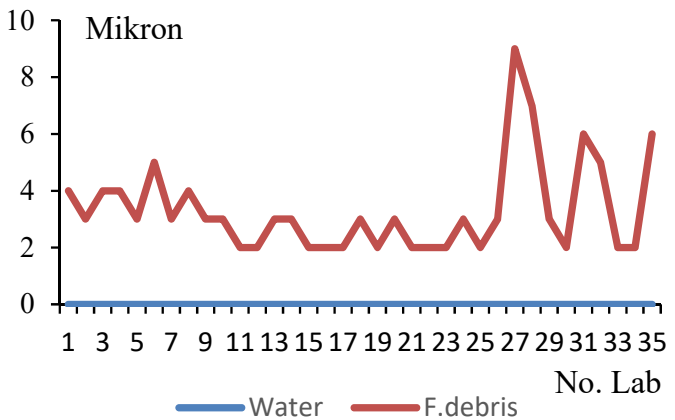

Gambar 6. Grafik Physical Test.

Kontaminasi fuel dapat menurunkan kadar pelumas. Oli tidak memiliki lapisan penguat yang dibutuhkan untuk memperkuat ketahanan gesekan antar logam sehingga dapat merusak bearing dan melonggarkan piston.

\section{Analisis Engine Speed}

Gambar 7 menunjukkan putaran mesin saat di atas nilai standard atau permissible (batas yang diijinkan). Pada engine SAA12V140E-3 standard engine speed adalah $2300 \mathrm{rpm}$, sedangkan engine speed yang diijinkan adalah $2400 \mathrm{rpm}$. Unit mengalami over speed yang menyebabkan roda memutar engine dimana seharusnya engine yang memutar roda. Kondisi jalan merupakan penyebab terjadinya engine over speed.

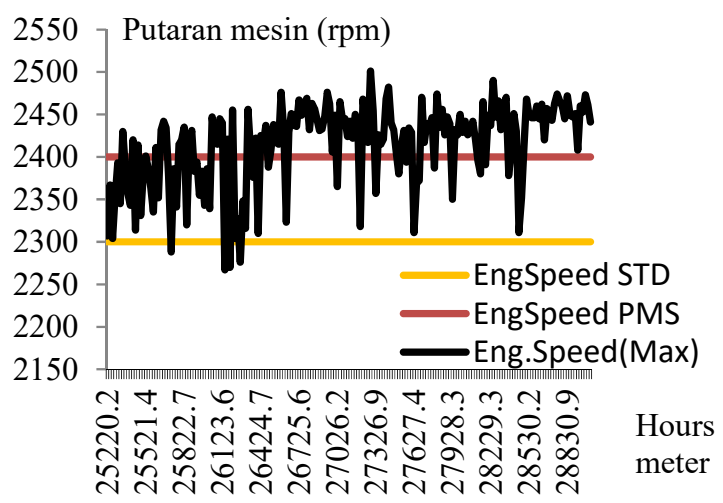

Gambar 7. Grafik engine speed.

\section{Analisis Engine Blow by}

Data hasil engine blow by menunjukkan nilai diatas standard dan permissible. Hal ini terkait dengan fenomena sering muncul asap berwarna putih yang

Jurnal Material Teknologi Proses (ISSN: 2477 - 2135), Volume 2, Nomor 1, Tahun 2021

DOI: $10.22146 /$ jmtp.66065 
keluar dari muffler dan penurunan tenaga mesin yang signifikan.

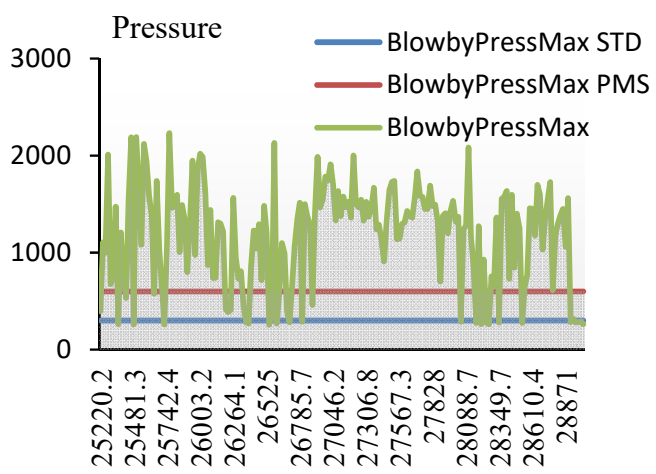

Gambar 8. Grafik blow by.

Setelah dilakukan overhaul pada engine, diketahui bahwa penyebab blow by yang tinggi adalah kerusakan cylinder head packing. Hal ini bisa menyebabkan bocornya kompresi mesin sehingga tidak dapat dinyalakan kembali dari keadaan mesin mati. Selain kebocoran packing cylinder head, cylinder head bengkok saat terjadi overheating sehingga menyebabkan munculnya celah tipis antara cylinder head, packing dan blok mesin. Kompresi mesin akan menurun atau bocor.

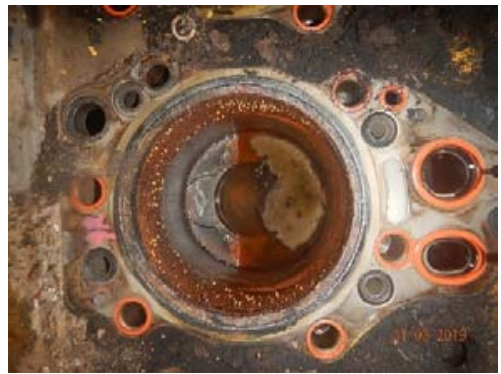

Gambar 9. Cylinder.

\section{Analisis Keausan Cylinder Liner}

Hasil pengukuran cylinder liner sebagaimana tertera pada Tabel 2, menunjukkan bahwa diameter inside cylinder liner pada bagian kanan mengalami keausan tertinggi $0,03 \mathrm{~mm}$ dan terendah $0,01 \mathrm{~mm}$. Keausan cylinder liner pada bagian kiri, tertinggi sebesar $0,03 \mathrm{~mm}$ dan terendah $0,00 \mathrm{~mm}$ atau tidak mengalami keausan. Semua cylinder liner memiliki roundness sebesar $0.01 \mathrm{~mm}$.

Semua cylinder liner pada bagian A (pengukuran $20 \mathrm{~mm}$ dari atas) memiliki keausan yang sama yaitu $0,03 \mathrm{~mm}$, sedangkan pada bagian B memiliki keausan bervariasi antara $0,01 \mathrm{~mm}$ hingga $0,03 \mathrm{~mm}$. Berikutnya cylinder liner bagian $\mathrm{C}$ (pengukuran $20 \mathrm{~mm}$ dari bawah) memiliki tingkat keausan tertinggi hanya 0,02 $\mathrm{mm}$ dan pada bagian sumbu $\mathrm{Y}$ dari silinder liner $1 \mathrm{~L}$ (silinder 1 bagian kiri) tidak memiliki keausan. Engine SAA12V140E-3 memiliki cylinder liner dengan standar ukuran $140 \mathrm{~mm}$, toleransi $0,02 \mathrm{~mm}$, serta memiliki standar roundness maksimal 0,02 $\mathrm{mm}$.
Berdasarkan data pada Tabel 2 dapat disimpulkan bahwa semua cylinder liner masih dalam batas spesifikasi.

Tabel 2. Pengukuran cylinder liner

\begin{tabular}{|c|c|c|c|c|c|c|}
\hline \multirow{3}{*}{$\begin{array}{c}\text { NOMOR } \\
\text { LINER }\end{array}$} & \multicolumn{6}{|c|}{ BAGIAN PENGUKURAN } \\
\hline & \multicolumn{2}{|c|}{$\mathbf{A}$} & \multicolumn{2}{|c|}{ B } & \multicolumn{2}{|c|}{$\mathbf{C}$} \\
\hline & $\mathbf{X}-\mathbf{X}^{\prime}$ & $\mathbf{Y}-Y^{\prime}$ & $\mathbf{X}-\mathrm{X}^{\prime}$ & $\mathbf{Y}-\mathbf{Y}^{\prime}$ & $\mathbf{X}-\mathbf{X}^{\prime}$ & $\mathbf{Y}-\mathbf{Y}^{\prime}$ \\
\hline LINER 1R & 140,03 & 140,03 & 140,03 & 140,03 & 140,02 & 140,02 \\
\hline LINER 2R & 140,03 & 140,03 & 140,01 & 140,02 & 140,02 & 140,01 \\
\hline LINER 3R & 140,03 & 140,03 & 140,03 & 140,03 & 140,02 & 140,02 \\
\hline LINER 4R & 140,03 & 140,03 & 140,03 & 140,02 & 140,01 & 140,02 \\
\hline LINER 5R & 140,03 & 140,03 & 140,02 & 140,02 & 140,02 & 140,02 \\
\hline LINER 6R & 140,03 & 140,03 & 140,02 & 140,03 & 140,02 & 140,02 \\
\hline LINER 1L & 140,03 & 140,03 & 140,03 & 140,02 & 140,01 & 140 \\
\hline LINER 2L & 140,03 & 140,03 & 140,02 & 140,02 & 140,02 & 140,01 \\
\hline LINER 3L & 140,03 & 140,03 & 140,03 & 140,03 & 140,01 & 140,02 \\
\hline LINER 4L & 140,03 & 140,03 & 140,01 & 140,03 & 140,01 & 140,02 \\
\hline LINER 5L & 140,03 & 140,03 & 140,01 & 140,02 & 140,02 & 140,02 \\
\hline LINER 6L & 140,03 & 140,03 & 140,03 & 140,03 & 140,01 & 140,01 \\
\hline
\end{tabular}

Keausan cylinder liner diakibatkan oleh kontak kering dengan ring priston. Ttingkat keausan di cylinder liner sangat dipengaruhi oleh material komponen, geometri kontak kedua komponen (ukuran dan kekasaran permukaan) dan kondisi operasi (tekanan dan pelumasan). Keausan dinding silinder dari data pada Gambar 10 bernilai cukup besar pada titik mati atas (top dead center), dimana hal ini akibat kegagalan proses pelumasan.

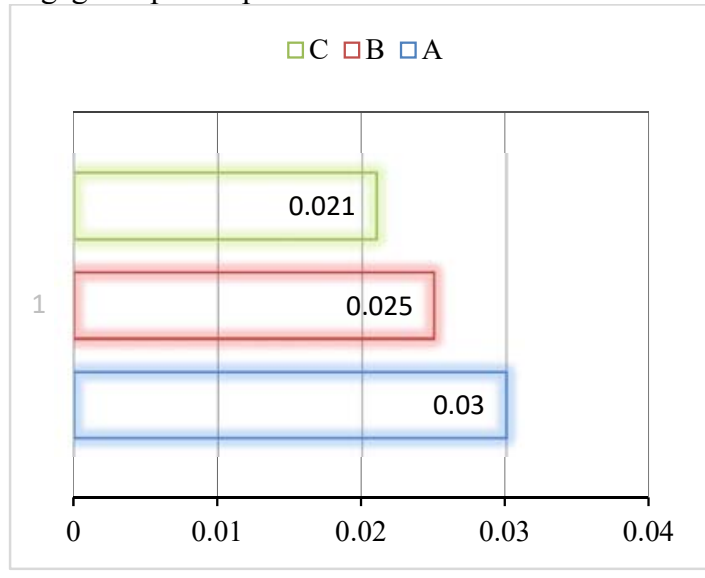

Gambar 10. Tingkat keausan cylinder liner

Gambar 9 menunjukkan hasil pemeriksaan visual pada cylinder liner yang mengalami keausan jenis abrasive wear. Cylinder liner mengalami keausan pada permukaan dalam yang bergesekan dengan piston dan ring piston. Keausan ini akibat kurangnya pelumasan pada bagian antara cylinder liner dengan ring piston, sehinggga terjadi gesekan secara langsung antara kedua komponen tersebut. Goresan-goresan pada cylinder liner sering muncul pada permukaan aus sepanjang gerakan piston. Hal ini meningkatkan kebutuhan akan 
minyak pelumas sekaligus mengurangi performa pembakaran. keausan dan goresan pada cylinder liner dapat mengurangi umur dari komponen tersebut.

\section{Analisis Keausan Main Metal}

Data pengukuran thick main metal pada Tabel 3 menunjukkan bahwa nilai keausan tertinggi adalah 0,03 $\mathrm{mm}$. Hal ini diperoleh dari pengukuran ketebalan main metal sebesar 4,47 mm, sedangkan standar ukurannya adalah 4,50 mm. Hasil pengukuran ini juga menunjukkan beberapa titik yang tidak mengalami keausan.

Tabel 3. Pengukuran thick main metal

\begin{tabular}{ccccccc}
\hline \multirow{2}{*}{ DATA PENGUKURAN THICK MAIN METAL } \\
\hline \multirow{2}{*}{ MAIN } & \multicolumn{3}{c}{ BAGIAN PENGUKURAN } \\
\cline { 2 - 7 } METAL & \multicolumn{2}{c}{ A } & \multicolumn{3}{c}{ B } \\
\cline { 2 - 7 } & AX & AY & BX & BY & CX & CY \\
\hline 1 UP & 4,47 & 4,47 & 4,48 & 4,48 & 4,47 & 4,48 \\
\hline 2 UP & 4,47 & 4,48 & 4,5 & 4,47 & 4,48 & 4,49 \\
\hline 3 UP & 4,47 & 4,48 & 4,49 & 4,5 & 4,5 & 4,48 \\
\hline 4 UP & 4,46 & 4,47 & 4,47 & 4,47 & 4,49 & 4,47 \\
\hline 5 UP & 4,48 & 4,48 & 4,5 & 4,47 & 4,48 & 4,48 \\
\hline 6 UP & 4,49 & 4,47 & 4,47 & 4,48 & 4,5 & 4,48 \\
\hline 7 UP & 4,5 & 4,47 & 4,47 & 4,48 & 4,5 & 4,47 \\
\hline 1 BTM & 4,47 & 4,49 & 4,5 & 4,49 & 4,49 & 4,48 \\
\hline 2 BTM & 4,5 & 4,5 & 4,47 & 4,47 & 4,48 & 4,48 \\
\hline 3 BTM & 4,49 & 4,5 & 4,47 & 4,48 & 4,5 & 4,47 \\
\hline 4 BTM & 4,5 & 4,5 & 4,48 & 4,48 & 4,49 & 4,48 \\
\hline 5 BTM & 4,5 & 4,5 & 4,47 & 4,49 & 4,49 & 4,5 \\
\hline 6 BTM & 4,48 & 4,49 & 4,48 & 4,49 & 4,48 & 4,48 \\
\hline 7 BTM & 4,5 & 4,5 & 4,47 & 4,47 & 4,49 & 4,48 \\
\hline
\end{tabular}

Gambar 11 menunjukkan hasil pemeriksaan visual pada main metal yang mengalami keausan jenis abrasive wear. Nampak bahwa bearing mengalami keausan pada permukaan. Keausan ini diakibatkan oleh aliran pelumas pada main metal yang kurang sempurna. Akibatnya terjadi gesekan langsung antara main metal dan main journal crankshaft.

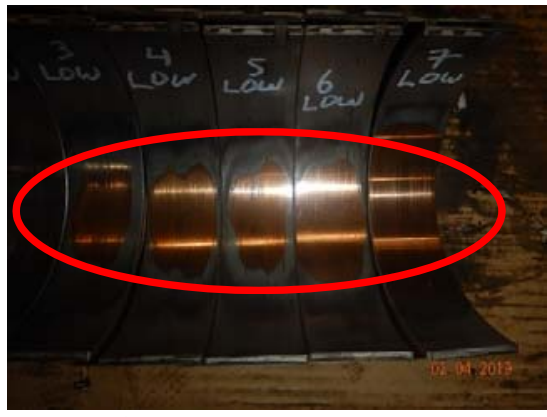

Gambar 11. Keausan main metal.

\section{Analisis Program Pemeriksaan Mesin}

Data tabel 4 merupakan data hasil pemeriksaan mesin selama tiga periode sebelum proses overhaul.
Dari data tersebut terlihat bahwa sebelum dilakukan overhaul, mesin masih dalam kondisi baik. Semua hasil pengujian PPM dalam kondisi standar dan permissible. Namun terlihat bahwa mesin mengalami penurunan performa pada beberapa sistem. Hal ini menyebabkan unit tidak dapat bekerja dengan maksimal.

Tabel 4. Data PPM

\begin{tabular}{|c|c|c|c|c|}
\hline \multicolumn{5}{|c|}{$P P M$} \\
\hline Data & STD & I & II & II \\
\hline \multirow{3}{*}{$\begin{array}{l}\text { Engine Speed } \\
\text { (RPM) }\end{array}$} & $625-675$ & 625 & 655 & 655 \\
\hline & $2200-2300$ & 2207 & 2210 & 2198 \\
\hline & $1550-1750$ & 1670 & 1650 & 1590 \\
\hline $\begin{array}{l}\text { Blow-by } \\
\text { Pressure } \\
\left(\mathrm{mmH}_{2} 0\right)\end{array}$ & $\begin{array}{c}\text { Max. } 300 \text { / } \\
\text { Max. } 600\end{array}$ & 230 & 190 & 135 \\
\hline \multirow{2}{*}{$\begin{array}{l}\text { Lub Oil } \\
\text { Pressure } \\
(\mathrm{kg} / \mathrm{cm} 2)\end{array}$} & $1 / 0,7$ & 1.8 & 1.7 & 2 \\
\hline & $\begin{array}{c}3-5 \text { / Min. } \\
2\end{array}$ & 4.25 & 3.8 & 4.5 \\
\hline \multirow{3}{*}{$\begin{array}{l}\text { Boost } \\
\text { Pressure LH } \\
(\mathrm{mmHg})\end{array}$} & $\begin{array}{c}\text { Min. } 950 / \\
\text { Min } 850 \\
\end{array}$ & 1000 & 850 & 1000 \\
\hline & - & 150 & 250 & 350 \\
\hline & - & 200 & 300 & 400 \\
\hline \multirow{3}{*}{$\begin{array}{l}\text { Boost } \\
\text { Pressure RH } \\
(\mathrm{mmHg})\end{array}$} & $\begin{array}{c}\text { Min. } 950 / \\
\text { Min } 850\end{array}$ & 1050 & 900 & 950 \\
\hline & - & 200 & 250 & 350 \\
\hline & - & 250 & 300 & 400 \\
\hline $\begin{array}{l}\text { Ambient } \\
\text { Temp. }\left({ }^{\circ} \mathrm{C}\right)\end{array}$ & - & 30 & 30 & 30 \\
\hline \multirow{2}{*}{$\begin{array}{l}\text { Exhaust Gas } \\
\text { Temp. LH } \\
\left({ }^{\circ} \mathrm{C}\right)\end{array}$} & $\begin{array}{c}\text { Max. } 700 / \\
\operatorname{Max} 750\end{array}$ & 605 & 630 & 572 \\
\hline & $\begin{array}{c}\operatorname{Max} .700 / \\
\operatorname{Max} 750\end{array}$ & 594 & 596 & error \\
\hline \multirow{2}{*}{$\begin{array}{l}\text { Exhaust Gas } \\
\text { Temp. RH } \\
\left({ }^{\circ} \mathrm{C}\right)\end{array}$} & $\begin{array}{c}\text { Max. } 700 / \\
\operatorname{Max} 750\end{array}$ & error & 248 & error \\
\hline & $\begin{array}{c}\text { Max. } 700 / \\
\operatorname{Max} 750\end{array}$ & error & 396 & error \\
\hline
\end{tabular}

\section{Analisis dyno test}

Data dyno test pada Gambar 13, menunjukkan bahwa engine memiliki performa yang lebih baik daripada sebelum proses overhaul. Hal ini dikarenakan saat overhaul, semua komponen yang aus telah diganti dengan komponen yang baru.

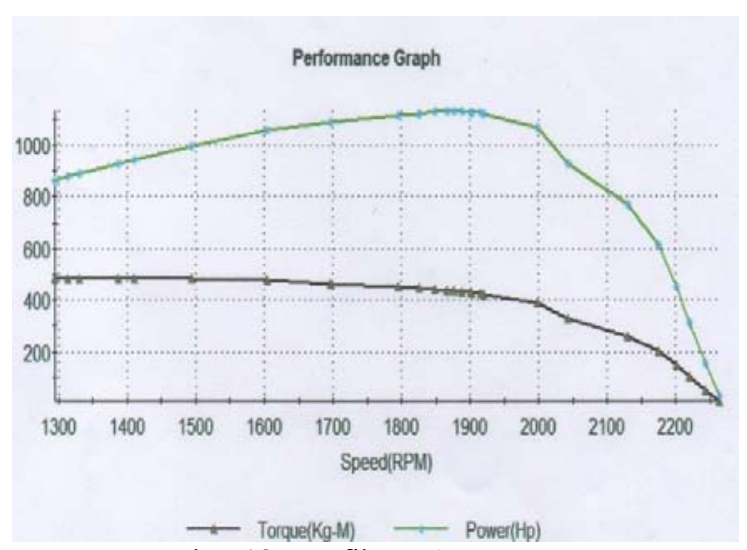

Gambar 12. Grafik performance test. 


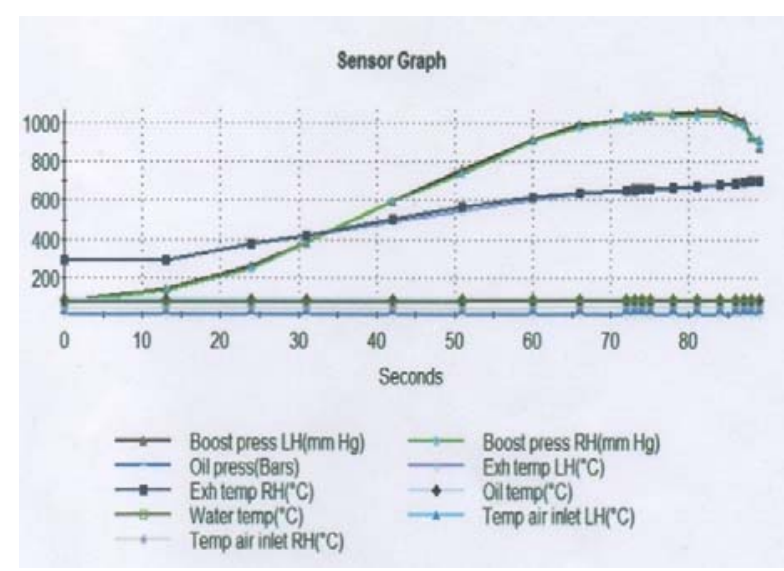

Gambar 13. Grafik sensor graph.

Tabel 4. Data hasil uji running test.

\begin{tabular}{|c|c|c|c|c|}
\hline & \multicolumn{4}{|c|}{ Running test } \\
\hline \multirow[t]{2}{*}{ No. } & \multicolumn{2}{|c|}{ Standard (manual) } & \multicolumn{2}{|c|}{ Actual (tested) } \\
\hline & RPM & HP & RPM & HP \\
\hline 1 & 650 & 0 & & \\
\hline 2 & 1000 & 75 & & \\
\hline 3 & 1250 & 197 & & \\
\hline 4 & 1550 & 489 & & \\
\hline 5 & 1800 & 852 & & \\
\hline 6 & 1900 & 1200 & 1902 & 1127 \\
\hline
\end{tabular}

Performa yang didapatkan setelah proses overhaul ini adalah sebesar $\frac{1127}{1200} \times 100 \%$ atau 94\%. Performa ini cukup baik, mendekati kemampuan engine dalam keadaan baru.

\section{KESIMPULAN}

1. Tingkat keausan inner part berdasarkan data program analisis pelumas masih normal.

2. Performa engine selama pengoperasian berdasarkan data Vehicle Health Monitoring System (VHMS) mengalami penurunan dan engine dapat dinyatakan abnormal.

3. Performa engine sebelum proses overhaul berdasarkan data program pemeriksaan mesin (PPM) masih sesuai standar dan permissible.

4. Keausan inner part setelah engine overhaul masih sesuai standar dan permissible.

5. Performa engine setelah proses overhaul berdasarkan data dyno test adalah $94 \%$.

\section{Referensi}

[1] Al Amien, 1994, "Laju dan Mekanisme Keausann Abrasive Bahan Komposit Karbon Vinyl/Ester", Thesis, Universitas Indonesia, Jakarta.

[2] Tarina, D., dan Kaelani, Y., 2012, "Studi Eksperimental Laju Keausan (Secisif Wear Rate) Resin Akrilik dengan Penambahan Serat Penguuat pada Detal Prosthesis", Jurnal Teknik Mesin Surabaya.
[3] Heywood, J.B., 1988, Internal Combustion Engine Fundamental, McGraw Hill Inc., New York.

[4] Bale, J.S., 2009, "Pengaruh faktor Keausan Die Drawn UHMWPE akibat Tegangan Kontak untuk Aplikasi Sendi Lutut Tiruan", Jurnal Teknik Mesin UNC Kupang.

[5] PT Trakindo, 2011, Applied Failure Analysis Buku Panduan Siswa, Training Center PT Trakindo, Cileungsi.

[6] Syaiful, 2012, Teknologi Motor Diesel. Bandung, Alfabeta. 